\section{NHS dental professionals' evaluation of a child protection learning resource}

\author{
J. C. Harris, ${ }_{1}^{1}$ J. Bradbury, ${ }_{1}^{2}$ J. Porritt, ${ }^{3}$ F. Nilchian ${ }^{4}$ and C. D. Franklin ${ }^{5}$
}

IN BRIEF

- Confirms that a widely-distributed child protection learning resource for the dental team has been widely used.

- Shows this has had a significant impact on practitioners' self-reported knowledge, confidence and practice organisation.

- Enables readers to consider whether they themselves may find the resource useful for continuing professional education.

The aim of this survey was to evaluate the impact of an educational child protection resource which had been developed and made available, free of charge, to all NHS dental practices and salaried primary dental care services in England and concurrently published online. A postal questionnaire was sent to a random sample of 1000 NHS dental practices to assess whether the learning objectives of the educational resource had been met. A total of 467 questionnaires were completed (46.7\% response rate). Almost two thirds of participants (63.4\%) remembered receiving the Child Protection and Dental Team (CPDT) handbook or seeing the website and almost all of them had used (looked at or read) it and felt able to access it if needed. Of the 265 users, 76.2\% felt it had improved their knowledge of child protection, 60.5\% had adopted a child protection policy, 53.7\% had identified a child protection lead and $25.8 \%$ had arranged further training as a result of using the educational resource. The findings from the evaluation indicated that the learning objectives of the CPDT educational resource had been met and highlighted ways in which the resource could be further improved to effectively meet the needs of dental professionals.

\section{INTRODUCTION}

UK dental professionals are required by statutory guidance to work together with others to safeguard children ${ }^{1-3}$ and by ethical standards guidance to find out about and follow local child protection procedures. ${ }^{4}$ Indeed, many dentists who regularly treat children report that managing dental neglect is part of daily practice. ${ }^{5}$ However, previous research has shown that dentists feel unprepared to take on a child protection role and are unsure what to do if they suspect that a child has been maltreated. ${ }^{6-8}$ In 2005, the Department of Health (England) commissioned a working group to develop an educational resource on child protection for primary care dental teams. ${ }^{9}$ Working in association with the

\footnotetext{
${ }_{1}$ Specialist in Paediatric Dentistry, Sheffield Salaried Primary Dental Care Service, Firth Park Dental Clinic, North Quadrant, Sheffield, S5 6NU; ${ }^{2}$ Senior Lecturer in Nutrition, School of Life Sciences, Kingston University, Kingston upon Thames, KT1 2EE, ${ }^{3}$ Research Assistant, ${ }^{4} \mathrm{PhD}$ Student, Unit of Dental Public Health, University of Sheffield, Claremont Crescent, Sheffield, S10 2TA, ${ }^{5}$ Postgraduate Dean, Regional Postgraduate Dental Education Office, Don Valley House, Savile Street East, Sheffield, S4 7U0 ${ }^{*}$ Correspondence to: Dr Jenny Harris Email: jenny.harris@nhs.net
}

\section{Refereed Paper}

Accepted 4 November 2010

DOI: 10.1038/sj.bdj.2011.3

${ }^{\circledR}$ British Dental Journal 2011; 210: 75-79
Committee of Postgraduate Dental Deans and Directors (COPDEND), the working group designed the 'Child Protection and the Dental Team' handbook and website to give all members of the dental team a basic awareness of child protection issues so as to encourage them to identify local contacts for advice and referral.

The content of the handbook was organized into five sections: 'Responsibility' (the responsibility of the dental team to be knowledgeable about child protection), 'Recognising' (how to recognise abuse and neglect), 'Responding' (what to do if abuse or neglect is suspected), 'Reorganising' (making organisational changes within the practice to meet child protection responsibilities) and 'Resources' (additional information to photocopy/download). The handbook was sent free of charge to all NHS dental practices and salaried primary dental care services (c. 9,000) in England in May/June 2006 and the website published concurrently (http://www.cpdt.org.uk/). Different distribution arrangements applied in other parts of the United Kingdom.

\section{AIM AND OBJECTIVES}

The aim of this project was to evaluate dental practitioners' opinions and use of the CPDT learning resource. The specific objectives of this study were to assess whether practitioners from NHS dental practices remembered receiving the resource, had used it, found it useful and had changed their practice as a result.

\section{MATERIALS AND METHODS}

\section{Subjects and design}

Written confirmation from the National Research Ethics Service, which indicated that formal ethical approval was not necessary for this service evaluation, was obtained before commencement of the study. A sample size of 500 was selected to yield a 95\% confidence interval of $\pm 5 \%$, assuming $30 \%$ of participants recalled receiving the resource. We anticipated a 50\% response rate after two mailings. Therefore, questionnaires were mailed out to a random sample of 1000 dental practices with NHS contracts from the NHS Business Service Authority (NHS BSA)'s database in September 2008. This was two years after the dental practices should have received their copy of the educational resource (May/June 2006) distributed by the same method. The covering letter asked the recipient to complete the questionnaire 
or to pass it on to the relevant lead person in the practice if that was not her/him. Each questionnaire had a unique identifying number, which was linked to an address, to ensure anonymity. A second copy of the questionnaire was sent to those practices which had not responded after one month.

The two authors of this paper (JCH, $\mathrm{CDF}$ ) who were also members of the CPDT authorship team and working group had no involvement in the administration of the survey, data entry and analysis.

The design of the evaluation questionnaire was informed by a recent Cochrane systematic review on increasing response rates to postal questionnaires ${ }^{10}$ and comprised one A3-sized sheet of paper printed on both sides in colour and folded to produce an A4-sized 'booklet', with the questions on the two inside pages only. A copy of the questionnaire may be obtained from the corresponding author. Cognitive interviews were conducted with eight dental professionals responsible for child protection to check for their understanding and interpretation of the questions included within the questionnaire ${ }^{11}$ and minor modifications were made as a result of this process to improve clarity.

\section{Outcome measure}

The self-completion questionnaire obtained demographic information on the staff member's age, gender and job role within the dental practice. In order to identify which practices would have received a copy of the resource the questionnaire asked staff to indicate whether their practice had held an NHS contract in May/June 2006. The questionnaire also consisted of closed questions requiring either yes/no answers or the selection of a response from a five-point Likert scale to indicate strength of agreement/disagreement. Information obtained included whether the handbook had been received and used to improve knowledge of child protection, which actions had been implemented as a result of using the resource, and which other factors had influenced child protection knowledge, attitudes or practice in the past two years. Additionally, there were two open-ended questions that asked dental practitioners to provide feedback on what they found the most useful about the CPDT resource and what they

Table 1 Characteristics of NHS dental practice participants who had used (looked at or read) the resource $(n=265)$

\begin{tabular}{|c|c|c|c|}
\hline & & \multicolumn{2}{|c|}{ Used the resource } \\
\hline & & $\%$ & $n$ \\
\hline \multirow[t]{2}{*}{ Gender } & Female & 42.8 & 113 \\
\hline & Male & 57.2 & 151 \\
\hline \multirow[t]{6}{*}{ Job role } & Therapist/hygienist & 1.1 & 3 \\
\hline & Dental Nurse & 3.0 & 8 \\
\hline & Dentist & 75.0 & 198 \\
\hline & Practice manager & 16.7 & 44 \\
\hline & Receptionist & 2.7 & 7 \\
\hline & Other & 1.5 & 4 \\
\hline
\end{tabular}

Table 2 Impact of the educational resource (percentage of NHS dental practice participants who had used the resource answering 'yes')

Questionnaire item ${ }^{*}$

Have internet access at work (265)

Have internet access at work and have seen the website (249)

Could find the handbook or website if needed (226)

Have used the resource to improve knowledge of child protection...

\begin{tabular}{l|l|l|l|}
\hline i) personally (244) & 186 & 76.2 \\
\hline ii) as part of their dental team (244) & 167 & 68.4 \\
\hline iii) as part of wider group learning (209) & 51 & 24.4 \\
\hline As a result of using the resource the practice has... & 137 & 53.7 \\
\hline i) identified a staff member to lead on child protection (255) & 156 & 60.5 \\
\hline ii) adopted a written child protection policy (258) & 64 & 25.8 \\
\hline iii) arranged child protection training for one or more of the team (248) & & \\
\hline *Figures in brackets indicate number of responses to item & &
\end{tabular}

found least useful about the resource. Finally, they were invited to write any other feedback.

\section{Data analysis}

SPSS (version 16) was used to provide a descriptive analysis of the quantitative data. Qualitative data from the openended text questions were analysed using thematic content analysis. ${ }^{12}$

\section{RESULTS}

\section{Descriptive analysis}

Of the 1000 evaluation questionnaires sent to NHS dental practices, 473 were returned; one was 'undelivered'; five were uncompleted and 467 were completed (46.7\% response rate). However, 16 participants who had completed the questionnaire indicated that their dental practice did not have an NHS contract at the time the CPDT resource was distributed and were therefore excluded from the analysis, resulting in a sample size of 451 .

A total of $286(63.4 \%)$ remembered receiving or seeing the handbook or website and of this group 265 (92.6\%) had used (looked at or read) the resource. The subsequent analysis uses the responses from the 265 participants who had used the handbook or website. Most of the respondents who had used the resource were dentists (75.0\%) and the majority were male (57.2\%) (see Table 1). The age range was from 21 years to 72 years, with a mean age of 46.3 years ( $\mathrm{SD}=8.8$ years).

Three participants (1.2\%) had made a 


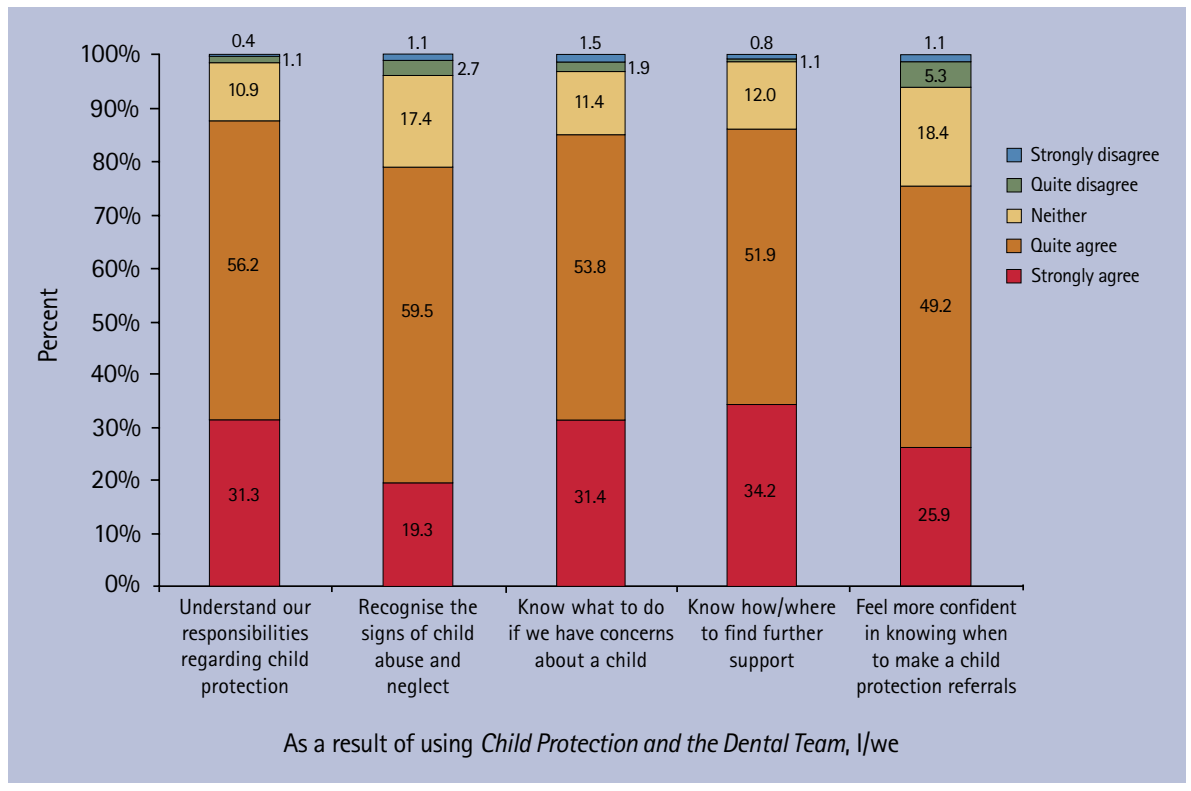

Fig. 1 The impact of the educational resource on practitioners' knowledge and practice of child protection

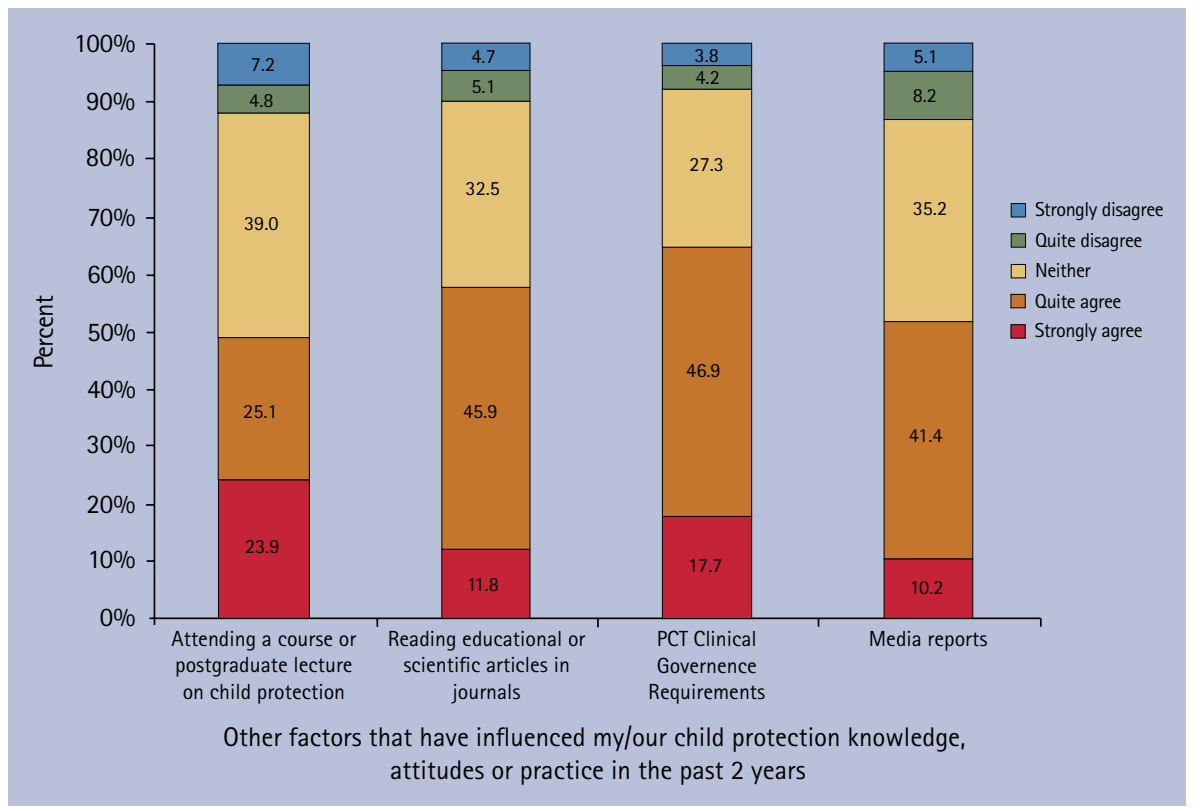

Fig. 2 Other factors which had influenced practitioners' knowledge, attitudes or practice around child protection

child protection referral in the previous two years; 259 had not made a referral and three could not remember.

\section{Use and impact of the educational resource}

Seventy-five percent of the participants had access to the internet at work and 23.3\% with workplace internet access had seen the CPDT website (Table 2). Most participants knew where to locate the handbook or website should they need it (90.3\%) and many had used at least one of these educational resources to improve their knowledge of child protection personally (76.2\%), as part of their dental team (68.4\%) and as part of wider group learning (24.4\%). As a result of using the resource, over half of participants had identified a member of staff to lead on child protection and had adopted a written child protection policy (53.7\% and 60.5\% respectively). Around one quarter of participants had arranged child protection training for themselves or other members of their team as a result of looking at the resource (25.8\%).

Participants' views on the effect of the resource on their knowledge of child protection were very positive. More than three quarters of the staff from NHS dental practices agreed or strongly agreed that, in the two-year period since receiving the CPDT resource, the resource had increased their knowledge of their responsibilities, how to recognise child abuse and neglect, what to do if concerned, where to find support and further information and increased confidence in knowing when to make a child protection referral (see Figure 1).

Figure 2 summarises the other factors that had influenced the child protection knowledge, attitudes and practice of practitioners in the two year period since receiving the CPDT handbook. Almost two thirds of participants reported being influenced by NHS Primary Care Trust (PCT) Clinical Governance requirements (64.6\%), more than half of participants had been influenced by media reports (51.6\%) and educational or scientific journals (57.7\%) and almost half had been influenced by attendance at a continuing professional development (CPD) course on this topic $(49.0 \%)$.

\section{Positive feedback on the educational resource}

Dental practitioners provided positive feedback on many different elements of the educational resource including the presentation of the booklet and website, the practical information included in the resource and the impact of the educational resource on influencing and developing their practice in this area.

In relation to the presentation of resource, the layout, ease of use, clarity and appropriateness of the language were all praised:

'The general layout and sections make it quite a readable source of quite a difficult subject'

'The website was very informative and easy to navigate. Information easily found'

Participants felt that the practical information included within the resource (for example, signs of child abuse and neglect) was particularly useful. Documents in the 'Resources' section, which could be photocopied or downloaded, also attracted favourable comments. Among these, the 'flowchart for action', which summarises the steps that should be taken when there are concerns about the welfare of a child, 
was the most popular document within the resource. Participants also commented on the usefulness of including contact information for further information and advice:

'Flowchart for referral - outlining the procedures in a straightforward and unambiguous manner'

'Guidance for observing signs of abuse'

'Most relevant was who/where/how to contact professionals for 'outside' help'

The value of the CPDT resource for developing practices related to child protection was also discussed. Practitioners spoke of how the resource had increased the dental team's awareness of the issue of child protection and had increased staff confidence and capability to meet their child protection responsibilities:

'Bringing awareness to the practice'

'Enabled us to audit our practice and develop further our practice'

'Help to set up child protection policy'

\section{Recommendations for how to improve the resource}

The analysis of participants' responses, including what they 'least liked' about the resource, enabled a series of recommendations to be developed for how the educational resource could be improved. These included the need for additional content in the resource, the provision of regular updates on the subject, making the resource more concise/brief and increasing the availability of the resource.

Some practitioners felt that additional information about who could be contacted for advice/information and case studies could have been included in the resource:

'Telephone numbers of who to contact locally for advice or central telephone number - who can then give telephone numbers for local help. Book has no help telephone numbers'

It was proposed that regular updates could be sent out to practices to keep staff informed about the issue of child protection and that amendments to the resource should be conducted and disseminated, as necessary:

'To send regular updates/amendments'

Some practitioners suggested that the resource would benefit from being shorter and more concise. A number of professionals felt that the length of the booklet was a potential barrier in the use of this resource by dental care staff:

'I understand it is complicated and very involved subject, which is very emotive and raises strong feelings; but I feel it should wherever possible be simplified. Something smaller and less formidable in volume would encourage other staff to read it'

'Should be a concise booklet that could be read over lunch'

Notably, a number of professionals indicated they would like to see the resource publicised more and made more widely available:

'Advertise website more'

'More copies for staff to take away'

A minority of participants commented that they did not find the resource useful and some felt that they received all the necessary information they required from attending courses or from existing policies/literature on the subject of child protection:

'Our PCT has its own comprehensive safeguarding children policy and procedures, training etc. For our service using this Child Protection and the Dental Team package would have been a confusing duplication'

'I find going to courses more helpful'

\section{DISCUSSION}

Interestingly, more than two years after the CPDT educational resource had been made available to NHS dental practices, two thirds of participants who should have received it remembered doing so and almost all of them felt they could locate the handbook or the website if needed. The booklet was more widely used than the website, suggesting that updating the website alone may not be an effective method of reaching most practices.

Over three quarters of practitioners who accessed the resource felt that the CPDT resource had influenced their knowledge of child protection (responsibilities, recognising signs of abuse, what to do, useful contacts, appropriate actions) and increased their confidence in knowing when to make a child protection referral. Around a half reported that their dental practice had adopted a written child protection policy as a result of receiving the handbook. Therefore, while previous research has found that written educational resources typically only have a small beneficial effect on professional practice, ${ }^{13}$ from the findings in this study, it appears that the CPDT resource did have a significant impact on practitioners' knowledge, confidence and practice organisation relating to child protection.

Approximately half of the practitioners felt that PCT clinical governance requirements, educational and scientific articles, courses and media reports had also influenced their attitudes, knowledge and practice around child protection. This reveals that practitioners develop their knowledge of child protection issues through a wide variety of methods.

Participants were overwhelmingly positive about the presentation of the educational resource and the usefulness of the information it included. Some staff discussed how using the resource had raised their awareness of child protection and described the different ways that it had directly influenced their practice. However, a number of recommendations for how the resource could be improved were suggested, which included: updating the resource regularly; raising dental practitioners' awareness of the booklet and website; and increasing the availability of the booklet to dental practices. Some staff also felt that the booklet should be shorter to encourage all members of the dental practice to read the resource. One method of encouraging staff to access the resource without compromising the depth of information provided in the CPDT handbook could be to develop a pocket or summary CPDT booklet, which contains basic information about child protection and signposts practitioners to specific sections of the CPDT handbook for more detailed information.

Although posted to the lead dentist at each practice, responses were received from non-dentists. This suggests that the child protection leadership role in dental practices is undertaken by different team members and that the resource had reached beyond dentists to staff who held other roles within the dental team. These observations support earlier findings from a 2007 survey of UK dental therapists, which revealed that $48 \%$ of dental therapists had a copy of the CPDT handbook. ${ }^{14}$ 
Furthermore, the resource had been used for both individual and team learning.

While the evaluation provided some insight into the impact of the CPDT educational resource on dental practitioners' practice, the study was not without limitations. It should be recognized that just under half of the NHS dental practitioners invited to participate in the study completed and returned evaluation questionnaires. It is possible that a proportion of those practices which did not participate in the study may have not held an NHS contract in May/June 2006 and, therefore, may never have received the CPDT resource. However, it is also possible that those staff who participated in the study had a particular interest in child protection or held strong opinions about the resource. Therefore, the perspectives and experiences of those staff who participated in the study may not be representative of all staff working in NHS dental practices.

It is not known whether increased knowledge and confidence actually resulted in practitioners taking appropriate action when concerned about a child. No baseline information on frequency of child protection referrals by the dental team is available for comparison. However, the finding that $1.2 \%$ of users had made a referral in the past two years confirms that dental practitioners are active in bringing children's needs to the attention of the agencies responsible for child protection and could consequently be instrumental in saving a child from ongoing maltreatment.

\section{CONCLUSION}

Approximately two thirds of dental staff who completed the evaluation questionnaire remembered receiving the CPDT educational resource. The majority of staff who had used the resource reported that it had made a positive contribution to their knowledge of child protection.

Our thanks go to the NHS BSA, those individuals who participated in the cognitive interviews and therefore helped in the design of the evaluation questionnaire and to all of the dental practitioners who took the time to complete the evaluation questionnaire. We would also like to acknowledge the positive contributions made by Dr Zoe Marshman and Professor Peter G. Robinson who provided advice on the conduct and interpretation of this evaluation. The handbook and website were funded by the Department of Health. However, the funding source had no involvement in the design of this study or collection, analysis and interpretation of data.

1. HM Goverment. Working together to safeguard children: a guide to inter-agency working to safeguard and promote the welfare of children. Nottingham: DCSF Publications, 2010. Available from: www. everychildmatters.gov.uk

2. HM Government. Statutory guidance on making arrangements to safeguard and promote the welfare of children under section 11 of the Children Act 2004. London: Department for Education and Skills, 2007.

3. Care Quality Commission. Outcome 7: Safeguarding people who use services from abuse. In Guidance about compliance: Essential standards of quality and safety, 2010. pp 92-101. London: Care Quality Commission, 2010. Available at http://www.cqc.org. uk/_db/_documents/Essential_standards_of_quality_and_safety_March_2010_FINAL.pdf.

4. General Dental Council. General Dental Council standards guidance: Standards for dental professionals. London: General Dental Council, 2005. Available at http://www.gdc-uk.org/ NR/rdonlyres/1B66D814-A197-4253-B331A2DB7F3254DC/0/StandardsforDental Professionals.pdf.

5. Harris J C, Elcock C, Sidebotham P D, Welbury R R. Safeguarding children in dentistry: 2. Do paediatric dentists neglect child dental neglect? Br Dent J 2009; 206: 465-470.

6. Lazenbatt A, Freeman R. Recognizing and reporting child physical abuse: a survey of primary healthcare professionals. J Adv Nurs 2006; 56: 227-236.

7. Welbury R R, MacAskill S G, Murphy J M et al. General dental practitioners' perception of their role within child protection: a qualitative study. Eur J Paediatr Dent 2003; 4: 89-95.

8. Cairns A M, Mok J Y, Welbury R R. The dental practitioner and child protection in Scotland. Br Dent J 2005; 199: 517-520.

9. Harris J, Sidebotham P, Welbury R et al. Child Protection and the Dental Team. An introduction to safeguarding children in dental practice. Sheffield: Committee of Postgraduate Dental Deans and Directors, 2006. Available from: www.cpdt.org.uk

10. Edwards P, Roberts I, Clarke M et al. Methods to increase response rates to postal questionnaires. Cochrane Database Syst Rev 2007; 2: MR000008.

11. Collins D. Pretesting survey instruments: An overview of cognitive methods. Qual Life Res 2003; 12: 229-238.

12. Silverman D. Interpreting qualitative data: methods for analysing talk, text and interaction. London: Sage, 1993.

13. Farmer A P, Légaré F, Turcot L et al. Printed educational materials: effects on professional practice and health care outcomes. Cochrane Database Syst Rev 2009; 3: CD004398.

14. Chadwick B L, Davies J, Bhatia S K, Rooney C McClusker N. Child protection training and experiences of dental therapists. Br Dent J 2009; 206: E6 